\title{
Study on the Influence of Campus Orienteering on the Overall Quality of College Students
}

\author{
Ruixue Cui ${ }^{1, a}$, Lina Su ${ }^{2, b}$ \\ ${ }^{1}$ Hebei University of Science and Technology, Shijiazhuang, 050018, China \\ ${ }^{2}$ Hebei University of Science and Technology, Shijiazhuang, 050018, China \\ aemail: zyxcrx@163.com, bemail: 441978319@qq.com
}

Keywords: campus orienteering, college students, overall quality, influence

\begin{abstract}
The introduction of orienteering into college strongly promotes the traditional teaching mode reform, which is beneficial to implement the guiding ideology of "Health First" and "Green Sports", and at the same time plays a positive role in the full implementation of quality education, the cultivation of students' innovation spirit and social adaption ability required by times and the deepening of college sports curriculum reform.
\end{abstract}

\section{Introduction}

Orienteering is a sport in which participants visit a number of flags (checkpoints) within the shortest possible time with the help of map and compass. It uses natural or artificial environment and combines intelligence and physical ability together, aiming at "keeping fit, exciting potential, melting team and sharpening the mind" and highlighting the educational idea of " people oriented". In addition, it is a well-designed practical activity with development and challenge. Orienteering is still an emerging sport for China's school physical education. As an expansion project of track and field course, it leads the students to the field from campus and promotes the diversified development of PE course. Some colleges take the lead in introducing orienteering into college PE class, which is not only the diversified development of traditional sports teaching resources , but also is a bold attempt to PE teaching innovation in the concept of developing and expanding "eco-sports" and "green sports". This paper discusses the influence of orienteering on the overall quality of students in depth according to the practice research of campus orientating carried out in schools, hoping to provide a valuable reference for the promotion of quality education development and the deepening of college PE curriculum reform.Objects and Methods of Study

\section{Objects and Methods of Study}

A. Objects of study

122 freshmen and sophomores who have PE curriculum are investigated, including 64 male and 58 female students, and they are divided into experimental class and control class

B. Methods of Study

1. Method of Document and Literature

2. Questionnaire Survey

Several rounds and also a number of psychological questionnaires are sent to students, to grasp the influence of campus orienteering on the overall quality of students.

3. Method of Mathematical Statistics

Changes in the physical fitness of students are measured and counted, and relative statistics and results of questionnaire are sorted out.

\section{Results and Analysis}

A. Improvement of Students' Interest in Sports

Orienteering is a sport with wits and courage, the fighting of physical strength and endurance as well as the contest of wisdom. Competitors have to learn the proper use of topographic map and 
compass and be good at observing the topography, to determine a scientific and accurate forward line. Wrong reading of map, improper use of compass or errors in judgment on the topography will result in a waste of physical strength and valuable time. In the teaching process of orienteering, participants have to carry out map comparison, route selection and search of the marked point of each checkpoint according to the direction of movement indicated on the map. Furthermore, as orienteering is carried out outdoors, participants can embrace nature and society, which enable them to release the pressure from living and learning and enjoy themselves.

B. Improvement of Physical Qualit

As orienteering is to run according to certain routes, fast speed determines the result in the contest provided that the target point is completed. The length of orienteering race is generally between $2 \mathrm{~km}$ to $20 \mathrm{~km}$, which would exercise participants' physical strength and endurance. In addition, orienteering requires speed change, direction change and obstacles overcoming according to the changes in topography and line. Therefore, it is much more difficult than the long-distance running in track and field, a small-size direction-change speed-change obstacles-overcoming marathon, which can greatly improve the physical fitness of participants. As long-distance running can improve the function of the circulatory and respiratory system, it is an excellent exercise and test for students' heart and lung function. At the same time, it can improve the overall quality of body like students' endurance, speed, sensitivity, coordination, jumping, balancing and so on. Campus orientation is guided by a comprehensive physical activity, so both outdoor survival skills training program and specific site courses have different levels of physical demands for students, which are embodied in the training process - achieving the purpose and requirements of the training on the basis of certain load. After the training, students' improvement in endurance, flexibility, agility, strength and other aspects at varying degrees is found by a test, and the excellent rate of quality standard test increases from $9.8 \%$ to $12.2 \%$.

Fig.1.CARDIOPULMONARY FUNCTION QUESTIONNAIRE

\begin{tabular}{|c|c|c|c|c|}
\hline \multirow{2}{*}{ Index } & \multicolumn{4}{|c|}{ Cardiopulmonary Function } \\
\cline { 2 - 5 } & \multicolumn{2}{|c|}{ Control group } & \multicolumn{2}{c|}{ Text group } \\
\cline { 2 - 5 } & Before & Back & Before & Back \\
\hline \multirow{2}{*}{ Quiet Heart Rate/ Time $\cdot$ min - 1 } & $75.12 \pm 4.78$ & $74.98 \pm 4.12$ & $75.01 \pm 4.12$ & $41.49 \pm 3.63$ \\
\hline Vital Capacity/mL & $3573 \pm 130.90$ & $3591 \pm 130.60$ & $3724 \pm 140.23$ & $3.17 \pm 4.73$ \\
\hline Maximal Oxygen Uptake/L & $2.51 \pm 5.48$ & $2.59 \pm 5.34$ & $2.87 \pm 5.68$ & 4.41 \\
\hline
\end{tabular}

\section{Obvious Enhancement of Image Recognition Ability}

The map consists of map scale, topographic symbols, feature symbols, magnetic north line, map geographical color, map legend annotation and symbol description table. Although Chinese Government has made great achievements in surveying and mapping industry and geographic information industry, the emphasis on scientific knowledge of map is not enough, and people have few effective ways to learn map knowledge. Seen from the statistics of first class, the vast majority of students know nothing about history, classification and function of map, and also are quite unfamiliar with topographic map. After systematic learning of map knowledge in orienteering teaching courses, most students can not only recognize the basic elements on a topographic map, master the basic skills of recognizing map and using map, but also can apply their map knowledge into life, such as going out navigation, mountain tourism, learning Geography and so on. It is confirmed by teaching practice that the implementation of orienteering is beneficial for students to master relevant map knowledge like recognizing map and using map, which has far-reaching significance for the popularization of Chinese students' map knowledge. 


\section{Improvement of Overall Judgment Ability}

While improves physical fitness, orienteering can also improve students' ability to solve and analyze problems and develop their logical thinking. There are a number of travel paths between two checkpoints in the orienteering map, which requires students to quickly and accurately choose a safe, fast and less energy-consumed route during the running. This is exactly the cultivation of students' ability to make a quick decision under difficulties like physical and intellectual pressure. In the training students would cross forest, climbing, jumping and mountain climbing are required in the cross, what's more, students have to make a right choice though rapid analysis and judgment according to the information provided in the map and combining natural characteristics. Orienteering trains participants' calmness, decisiveness and braveness, and these capabilities will subtly influence their continuous selection and judgment on the road of life, and finally achieve the goal, therefore, orienteering is also directional life.

E, Improvement of Adaptability and Innovation Ability

Due to the characteristics of orienteering, the location of each contest are not the same, even in the same contest, everyone's map, running route has changed substantially, and the selection of each route choice are subject to change based on individual physical strength, competitive state, landform and some other factors. Teaching and training are just the teaching of basic techniques and skills, and thus each contest requires students to design their own entry scheme and to determine their own route and heading direction according to their knowledge, experiences and also the site condition. Therefore, participation in orienteering can develop students' creative thinking and innovation. In the teaching, group project requires the cooperation of several students, and the participants with different characters, physical fitness and technologies have to cooperate with each other and reach a tacit understanding. As orienteering usually carries out in the wild, over a long period of teaching and training, students' awareness and utilizing ability of natural environment will be greatly improved, prevention and processing capacity of various common dangers and injury accidents, capacity for field activity and self-protection capacity will also be significantly improved.

FIG.2.SOCIAL ADAPTABILITY SELF-ASSESSMENT SURVEY

\begin{tabular}{|c|c|c|c|}
\hline \multirow{2}{*}{ Proportion } & \multicolumn{3}{|c|}{ social adaptability } \\
\cline { 2 - 4 } & <70(Maladaptive) & 70 85(The general ability to adapt) & $>$ 85(Strong ability to adapt \\
\hline Before the test & $30 \%$ & $60 \%$ & $10 \%$ \\
\hline After the test & $15 \%$ & $65 \%$ & $20 \%$ \\
\hline
\end{tabular}

F. Improvement of Cooperation Ability

Most current college students are the only child of family who is spoiled by their parents, and they have a good self-perception and high expectation. Once they come out of the shelter of their parents and confront with life and study independently, they do not know what to do and prone to have feelings of psychological imbalance, and even make some inappropriate behaviors. Questionnaire survey of students finds out that $27.6 \%$ of the students feel lonely or lost in social situations, $10.3 \%$ of the students can not live in harmony with others, $37.9 \%$ of the students often avoid to express their feelings, $27.6 \%$ of the students hate someone or are hated by others, $20.7 \%$ of the students feel their troubles can appeal to no one, 31\% of the students can not broadly listen to all views and $6.9 \%$ of the students are excluded.This shows that many students have social barriers more or less, such as suspiciousness, seclusiveness, self-contempt, shyness and so on. Campus orienteering is good at training interpersonal skill and team spirit. In the training, communication between students is multidirectional, the mode is diverse, and all participants work together, experience success and failure and enjoy a happy experience with bitterness in a common goal. Under this endemic atmosphere, every student is willing to open their hearts to establish mutual trust, understanding and caring between each other, and understands that helping others is helping themselves, in order to cultivate the teamwork spirit of mutual collaboration and mutual trust.Experimental data show that campus orienteering significantly reduces the proportion of 
students' maladaptive cases and students with strong adaptive ability increase greatly. Therefore, campus orienteering improves students' social adaptability and team collaboration capability, which lays a solid foundation for their smooth entry to society in the future.

G. Tempering Will and Cultivating Outstanding Quality

Orienteering teaching competition is to develop students' emotions and brave and indomitable will and also to emphasize mutual help in the teaching of orienteering. A saying is commonly heard in campus orienteering: "It is not that you can not, but you dare not; it is not the question of your ability, but your mentality." In the training, students will meet various difficulties and challenges. In this environment, whether they can timely adjust their mentality, control their emotions and take the first step decisively and courageously is the key to success. As can be seen from Table 1, campus orienteering enhances students' self-confidence and help overcome their own inertia, so that students become positive and their psychological health is also improved.Therefore, campus orienteering can cultivate good qualities like calmness, decisiveness, self-confidence, perseverance and so on, release all the energy of life and change the backward learning methods, so as to come into the the highest state of self-education and self-improvement and create a ideal self. Furthermore, campus orienteering can hone the perseverance to overcome difficulties, develop a healthy psychology and positive attitude towards life, improve and strengthen students' spirit of self-challenge, cultivate noble personality, so as to make participants a stronger person.

\section{Conclusion}

The promotion of orienteering in campus can improve the physical quality of students, promote the health of students, improve survival ability of students, train students's ability of independent thinking and difficulty solving, and help develop students' ability of rapid reaction and decisive judgment in the case of pressure. What's more, it helps expand content and space of school sports, and enhance students' ability of recognizing and using map and the quality defense of national quality. Through the practice of campus orienteering courses, it is found out that campus orienteering enables students to recognize their own potential and plays a positive role in enhancing self-confidence, improving mental capacity, improving students' interpersonal relation, cultivating teamwork spirit and maintaining physical and mental health.

\section{References}

[1] J.Q. Suo. "Technical Condition for the Setting of Orienteering Course in Ordinary Colleges," Shanghai, Journal of Shanghai Sports Academy, pp. 2-3, 2009

[2] X. Wang. “Orienteering Sports,” Beijing, Higher Education Press, pp. 18-20, 2009

[3] J.C. Hu, X.Z. Wu. “Orienteering Sports,” Hunan:Central South University Press, 2003.

[4] H.X. Zhong "The Henan Unviersities Orienteering Course feasibility study," Changchun University of Technology, vol2, pp. 155-157, 2006

[5] X.Z. He, W.H. Tang “ Orienteering,” Chang sha, Hunan Univercity Press, 2005

[6]H.S. Pan, S. Huang and H.Guo. "Research and Analysis about the Developing Status of Directional Cross country Sport in Colleges of Our Country," Guangzhou, Institute of Physical Education, vol2, pp. 51-53, 2003

[7] X.J. Chen " Orienteering Significance Analysis in our Country China Educational Technology \& Equipment,” China, Academic Journal Electronic Publishing House , vol33, pp. 98-99, 2011

[8] H.B. Luo Practice and study on the school Orienteering Teaching, $Z$ hej ian g Spo rt Se ien e e , vol26, pp. 84-87, 2004

[9] Y.M. Gu "Nanjing College Offers Directional Sports Curriculum Present Situation and Countermeasure Research,” Journal of Nanjing Institute of Physical Education( Natural Science), vol5, pp. 92-95, 2012 